\title{
PENGARUH PEMBERIAN KARBOL FUCHSIN DAN PEMANASAN SPUTUM SEBELUM PEMBUATAN SEDIAAN TERHADAP HASIL PEWARNAAN BTA
}

\author{
Mega Mirawati, Estu Lestari \\ Poltekkes Kemenkes Jakarta III \\ Email:megamirawati67@gmail.com
}

\begin{abstract}
Tuberculosis is an infectious disease caused by Mycobacterium tuberculosis. This disease is a health problem in the community. Minimal checks that need to be done to confirm pulmonary tuberculosis diagnostics are smear examinations. ZiehlNelseen method is an inspection method recommended by WHO. Sputum used to make preparations is a mucopurulent sputum. This can lead to infected laboratory workers if inhaled droplets containing Mycobacterium tuberculosis. This study aims to determine the effect of fuchsin carbolic acid and sputum heating before the preparation of the smear result. Temperature used $60^{\circ} \mathrm{C}, 70^{\circ} \mathrm{C}, 80^{\circ} \mathrm{C}$ and $90^{\circ} \mathrm{C}$ and control is sputum staining with Ziehl Neelsen method. The samples used positive smear sputum. The experimental research design and data were analyzed with Kruskal Wallis test. The research was conducted at the Bacteriology Laboratory of Medical Laboratory Technology Poltekkes Kemenkes Jakarta III in February to October 2016. The result of statistical test showed $p>0,301$ which means there was no significant difference between the dyeing result by using sputum which has been given carbolic fuchsin and heating before the preparation with the result staining method ZiehlNeelsen. The conclusion of this method can coloring Mycobacterium tuberculosis bacteria.
\end{abstract}

Keywords: Mycobacterium tuberculosis, BTA staining, sputum

\section{ABSTRAK}

Tuberculosis adalah penyakit infeksi disebabkan oleh Mycobacterium tuberculosis. Penyakit ini merupakan masalah kesehatan di masyarakat. Pemeriksaan minimal yang perlu dilakukan untuk memastikan diagnostik TB paru adalah pemeriksaan BTA. Metode Ziehl Nelseen merupakan metode pemeriksaan yang direkomendasikan oleh WHO.Sputum yang digunakan untuk membuat preparat adalah sputum yang mucopurulen.Hal ini dapat menyebabkan terinfeksinya petugas laboratorium bila terhirup droplet yang mengandung Mycobacterium tuberculosis. Penelitian ini bertujuan untuk mengetahui pengaruh pemberian karbol fuchsin dan pemanasan sputum sebelum pembuatan sediaan terhadap hasil pewarnaan BTA. Suhu yang digunakan $60^{\circ} \mathrm{C}, 70^{\circ} \mathrm{C}, 80^{\circ} \mathrm{C}$ dan $90^{\circ} \mathrm{C}$ dan kontrol adalah pewarnaan sputum dengan metode Ziehl Neelsen.Sampel yang digunakan adalah sputum BTA positif. Desain penelitian eksperimen dan data dianalisis dengan uji Kruskal Wallis. Penelitian dilaksanakan di Laboratorium Bakteriologi Jurusan TeknologiLaboratoriumMedis Poltekkes Kemenkes Jakarta III pada bulan Februari sampai Oktober 2016. Hasil uji statistik menunjukkan $p>0,301$ yang berarti tidak ditemukan perbedaan bermakna antara hasil pewarnaan dengan menggunakan sputum yang telah diberikan karbol fuksin dan pemanasan sebelum pembuatan sediaan dengan hasil pewarnaan metode Ziehl Neelsen.Kesimpulan metode ini dapat mewarnai bakteri Mycobacterium tuberculosis.

Kata Kunci: Mycobacterium tuberculosis, pewarnaan BTA, sputum 


\section{PENDAHULUAN}

Tuberculosis adalah penyakit infeksi disebabkan oleh Mycobacterium tuberculosis (Buntuan V,2014; Silvani H danSureskiarti E, 2016). Penyakit ini merupakan masalah kesehatan di masyarakat, baik dari sisi angka kematian (mortalitas), angkakejadian penyakit (morbiditas), maupun diagnosis dan terapinya(Depkes RI, 2007, Eddin GM dkk,2015).Tuberkulosis paru menempati peringkat ke empat sebagai penyakit pembunuh setelah penyakit jantung koroner, stroke, diabetes melitus dan hipertensi di wilayah perkotaan.

Indonesia menempati urutan ketiga di dunia setelah India dan China dalam hal jumlah penderita TB paru..Di Indonesia ditemukan penderita baru sekitar 583 ribu orang dan diperkirakan sekitar 140 ribu orangmeningal dunia tiap tahunnya (Depkes RI, 2007). Indonesia sebagai negara berkembang masih menjadi salah satu negara dengan kasus tuberkulosis paru tertinggi di dunia (WHO,2011)

Mycobacterium tuberculosis dapat menular dari individu satu ke individu lainnya melalui percikan droplet yang terbawa oleh udara seperti batuk, dahak atau percikan ludah (Susanto AD, 2010).Infeksi primer terjadi saat seseorang terpapar pertama kali dengan bakteri Mycobacterium
tuberculosis.Percikan dahak yang terhirup sangat kecil ukurannya, sehingga dapat melewati sistem pertahanan mukosilierbronkus, dan terus berjalan sehingga sampai di alveolus dan menetap disana. Infeksi dimulai saat bakteri berhasil berkembang biak dengan cara membelah diri di paru, yang mengakibatkan peradangan di dalam paru. Saluran limfe akan membawa bakteri ke kelenjar limfe disekitar hilus paru dan ini disebut sebagai kompleks primer. Waktu antara terjadinya infeksi sampai pembentukan kompleks primer adalah sekitar 4-6 minggu(Jawetz, E, Melnick.JL., Adelberg.E.A., 2013).

Pemeriksaan minimal yang perlu dilakukan untuk memastikan diagnostik TB paru adalah pemeriksaan BTA.Pemeriksaan mikroskopik BTA dari sputum memegang peran dalam men diagnosis awal atau pemantauan pengobatan tuberculosis (Susanti D, Kountul C dan Buntuan V, 2013). Pemeriksaan BTA metode Ziehl Nelseen merupakan metode pemeriksaan yang direkomendasikan oleh WHO. Sampel yang dibutuhkan untuk melakukan pemeriksaan ini adalah sputum. Sputum yang purulen akan dibuat coiling lalu setelah kering ditambahkan karbol fuksin dan dipanaskan sampai menguap.Pemanasan bertujuan untuk membuka dinding sel bakteri sehingga memudahkan dalam penyerapan zat warna. 
Hal ini disebabkan karena dinding sel $M$ tuberkulosis mengandung lapisan lemak yang sukar ditembus oleh zat warna.

Kekurangan dari cara ini adalah penggunaan sputum yang mengandung Mycobacterium tuberculosis yang masih hidup untuk membuat pereparat langsung. Hal ini dapat menyebabkan terinfeksinya petugas laboratorium bila terhirup droplet yang mengandung kuman $M$ tuberculosis yang berasal dari sputum tersebut. Aditama TY dan Luthni E tahun 2012 menyatakan bahwa tindakan tindakan yang sering menimbulkan pencemaran udara di laboratorium adalah pada saat membuka tempat sputum, membuat preparat langsung dan pada saat memanaskan sengkelit (ose).

Dinding sel bakteri Mycobacterium tuberculosis mengandung lemak dalam konsentrasi tinggi sehingga sukar menyerap zat warna, namun jika bakteri diberi zat warna khusus misalnya karbolfukhsin melalui proses pemanasan, maka akan menyerap zat warna dan akan tahan diikat tanpa mampu dilunturkan oleh peluntur yang kuat sekalipun seperti asamalkohol (Kumala W, 2006, Utji R, Harun H. 2015). Hal ini sama dengan sifat dari endospora yang tidak mudah diwarnai dengan zat pewarna pada umumnya, tetapi sekali diwarnai, zat warna tersebut akan sulit hilang. Kumala W (2006) menyatakan bahwa pewarnaan spora dengan metode Klein dilakukan dengan menambahkan suspensi bakteri dengan solutio fuchsin lalu dipanaskan menyebabkan mengembangnya lapisan luar spora sehingga zat warna utama dapat masuk ke dalam spora sehingga berwarna merah.

Pada penelitian ini pembuatan sediaan dilakukan setelah sputum ditambahkan karbol fuchsin dan dipanaskan sampai menguap. Penambahan zat warna dan pemanasan dapat mematikan bakteri Mycobacterium tuberculosis dan membuka dinding sel agar dapat menyerap zat warna. Kelebihan dari penelitian ini adalah pembuatan sediaan dilakukan setelah bakteri yang terdapat di dalam sputum sudah mati sehingga dapat mengurangi penyebab terjadinya infeksi bagi petugas laboratorium mikrobiologi. . Aditama TY dan Luthni E (2012) menyatakan bahwa resiko untuk terkena infeksi pada petugas laboratorium mikrobiologi 3-5 kali lebih tinggi daripada pekerja pekerja lain seperti petugas kantor dan lain lain.

Berdasarkan hal tersebut peneliti berkeinginan untuk meneliti tentang pengaruh penambahan karbol fuchsin dan pemanasan pada sputum sebelum pembuatan sediaan terhadap hasil pewarnaan BTA. 


\section{METODE}

Penelitian ini menggunakan desain penelitian eksperimen, dimana sampel sputum dibagi menjadi 4 kelompok percobaan yaitu pemanasan dengan suhu $60^{\circ} \mathrm{C}, 70^{\circ} \mathrm{C}, 80^{\circ} \mathrm{C}$ dan $90^{\circ} \mathrm{C}$ serta kontrol. Sampel yang digunakan adalah sputum BTA positif sebanyak 50 sampel Penelitian dilakukan di Laboratorium Bakteriologi Jurusan Teknologi Laboratorium Medis pada bulan Agustus sampai Oktober 2016.

Pada penelitian ini pembuatan preparat langsung dilakukan dengan cara masingmasing sampel sputum dibagi menjadi 4 tabung lalu pada setiap tabung ditambahkan karbol fuksin dengan perbandingan 1:1. Masing-masing tabung dipanaskan dalam waterbath dengan suhu berbeda yaitu tabung 1 dipanaskan pada suhu $60^{\circ} \mathrm{C}$, tabung ke 2 dipanaskan pada suhu $70^{\circ} \mathrm{C}$, tabung ke 3 dipanaskan pada suhu $80^{\circ} \mathrm{C}$ dantabung ke 4 dipanaskan pada suhu $90^{\circ} \mathrm{C}$ sampai menguap. Lalu dibuat hapusan pada sebuah kaca objek.Setelah pengeringan di udara, hapusan difiksasi lalu ditambahkan asam alkohol sampai warna merah karbol fuksin hilang. Setelah dicuci dengan air mengalir, sediaan digenangi dengan metilenbiru selama 1020 detik lalu dibilas dengan air mengalir dan dikeringkan.Kontrol adalah pewarnaan sputum dengan metode Ziehl Neelsen.

\section{HASIL DAN PEMBAHASAN}

Berdasarkan hasil penelitian terhadap 10 sampel sputum dengan BTA positip dengan perlakuan sputum terlebih dahulu diberi karbol fuchsin dan dipanaskan dengan beberapa suhu didapat hasil seperti tertera pada tabel 1 .

Tabel 1. Hasil pewarnaan dengan menggunakan beberapa suhu pemanasan.

\begin{tabular}{|c|c|c|c|c|c|}
\hline \multirow[t]{2}{*}{$\mathrm{NO}$} & \multirow[t]{2}{*}{ REPLIKASI } & \multicolumn{4}{|c|}{ HASIL PEWARNAAN } \\
\hline & & $60^{\circ} \mathrm{C}$ & $70^{\circ} \mathrm{C}$ & $80^{\circ} \mathrm{C}$ & $90^{\circ} \mathrm{C}$ \\
\hline 1 & $\mathrm{I}$ & $\begin{array}{c}\text { BTA merah } \\
\text { jelas, BTTA } \\
\text { dan lekosit } \\
\text { jelas }\end{array}$ & $\begin{array}{l}\text { BTA merah } \\
\text { jelas, BTTA } \\
\text { dan lekosit jelas }\end{array}$ & $\begin{array}{l}\text { BTA merah } \\
\text { jelas, BTTA } \\
\text { dan lekosit jelas }\end{array}$ & $\begin{array}{l}\text { BTA merah } \\
\text { jelas, BTTA } \\
\text { dan lekosit jelas }\end{array}$ \\
\hline 2 & II & $\begin{array}{l}\text { BTA merah } \\
\text { jelas, BTTA } \\
\text { dan lekosit } \\
\text { jelas }\end{array}$ & $\begin{array}{l}\text { BTA merah } \\
\text { jelas, BTTA } \\
\text { dan lekosit jelas }\end{array}$ & $\begin{array}{l}\text { BTA merah } \\
\text { jelas, BTTA } \\
\text { dan lekosit jelas }\end{array}$ & $\begin{array}{l}\text { BTA merah } \\
\text { tipis, BTTA dan } \\
\text { lekosit biru } \\
\text { jelas }\end{array}$ \\
\hline 3 & III & $\begin{array}{l}\text { BTA merah } \\
\text { jelas, BTTA } \\
\text { dan lekosit } \\
\text { jelas }\end{array}$ & $\begin{array}{c}\text { BTA merah } \\
\text { tipis, BTTA dan } \\
\text { lekosit biru } \\
\text { jelas }\end{array}$ & $\begin{array}{l}\text { BTA merah } \\
\text { jelas, BTTA } \\
\text { dan lekosit jelas }\end{array}$ & $\begin{array}{l}\text { BTA merah } \\
\text { jelas, BTTA } \\
\text { dan lekosit jelas }\end{array}$ \\
\hline
\end{tabular}




\begin{tabular}{|c|c|c|c|c|c|}
\hline 4 & IV & $\begin{array}{l}\text { BTA merah } \\
\text { jelas, BTTA } \\
\text { dan lekosit } \\
\text { jelas }\end{array}$ & $\begin{array}{c}\text { BTA merah } \\
\text { tipis, BTTA dan } \\
\text { lekosit biru } \\
\text { jelas }\end{array}$ & $\begin{array}{l}\text { BTA merah } \\
\text { jelas, BTTA } \\
\text { dan lekosit jelas }\end{array}$ & $\begin{array}{l}\text { BTA merah } \\
\text { tipis, BTTA dan } \\
\text { lekosit biru } \\
\text { jelas }\end{array}$ \\
\hline \multirow[t]{2}{*}{5} & V & $\begin{array}{l}\text { BTA merah } \\
\text { tipis, BTTA } \\
\text { dan lekosit }\end{array}$ & $\begin{array}{l}\text { BTA merah } \\
\text { tipis, BTTA dan } \\
\text { lekositbiru }\end{array}$ & $\begin{array}{l}\text { BTA merah } \\
\text { jelas, BTTA } \\
\text { dan lekosit jelas }\end{array}$ & $\begin{array}{l}\text { BTA merah } \\
\text { tipis, BTTA dan } \\
\text { lekosit biru }\end{array}$ \\
\hline & & birujelas & jelas & & Jelas \\
\hline 6 & VI & $\begin{array}{l}\text { BTA merah } \\
\text { tipis, BTTA } \\
\text { dan } \\
\text { lekositbirujelas }\end{array}$ & $\begin{array}{l}\text { BTA merah } \\
\text { tipis, BTTA dan } \\
\text { lekositbirujelas }\end{array}$ & $\begin{array}{l}\text { BTA merah } \\
\text { jelas, BTTA } \\
\text { dan lekosit jelas }\end{array}$ & $\begin{array}{l}\text { BTA merah } \\
\text { jelas, BTTA } \\
\text { dan lekosit jelas }\end{array}$ \\
\hline 7 & VII & $\begin{array}{l}\text { BTA merah } \\
\text { tipis, BTTA } \\
\text { dan } \\
\text { lekositbirujelas }\end{array}$ & $\begin{array}{l}\text { BTA merah } \\
\text { tipis, BTTA dan } \\
\text { lekositbirujelas }\end{array}$ & $\begin{array}{l}\text { BTA merah } \\
\text { tipis, BTTA dan } \\
\text { lekositbirujelas }\end{array}$ & $\begin{array}{l}\text { BTA merah } \\
\text { tipis, BTTA dan } \\
\text { lekositbirujelas }\end{array}$ \\
\hline 8 & VIII & $\begin{array}{c}\text { BTA merah } \\
\text { tipis, BTTA } \\
\text { dan } \\
\text { lekositbirujelas }\end{array}$ & $\begin{array}{l}\text { BTA merah } \\
\text { jelas, BTTA } \\
\text { dan lekosit jelas }\end{array}$ & $\begin{array}{l}\text { BTA merah } \\
\text { jelas, BTTA } \\
\text { dan lekosit jelas }\end{array}$ & $\begin{array}{l}\text { BTA merah } \\
\text { jelas, BTTA } \\
\text { dan lekosit jelas }\end{array}$ \\
\hline 9 & IX & $\begin{array}{l}\text { BTA merah } \\
\text { jelas, BTTA } \\
\text { dan lekosit } \\
\text { jelas }\end{array}$ & $\begin{array}{l}\text { BTA merah } \\
\text { tipis, BTTA dan } \\
\text { lekosit biru } \\
\text { jelas }\end{array}$ & $\begin{array}{l}\text { BTA merah } \\
\text { tipis, BTTA dan } \\
\text { lekosit biru } \\
\text { jelas }\end{array}$ & $\begin{array}{c}\text { BTA merah } \\
\text { jelas, BTTA } \\
\text { dan lekosit jelas }\end{array}$ \\
\hline 10 & $\mathrm{X}$ & $\begin{array}{l}\text { Tidakterwarnai } \\
\text {, BTTA dan } \\
\text { lekositbirujelas }\end{array}$ & $\begin{array}{l}\text { Tidakterwarnai, } \\
\text { BTTA dan } \\
\text { lekositbirujelas }\end{array}$ & $\begin{array}{l}\text { Tidakterwarnai, } \\
\text { BTTA dan } \\
\text { lekositbirujelas }\end{array}$ & $\begin{array}{l}\text { Tidakterwarnai, } \\
\text { BTTA dan } \\
\text { lekositbirujelas }\end{array}$ \\
\hline
\end{tabular}

Dari tabel 1 dapat diketahui bahwa didapat 15 sediaan dengan hasil pewarnaan tipis, 4 sediaan dengan tidak terwarnai dan 21 terwarnai dengan jelas.Kontrol sebanyak 10 sampel dengan hasil pewarnaan baik dan jelas.Untuk sediaan yang tidak terwarnai adalah sampel nomor 10 dengan karakteristik sampel agak encer dan bercampur banyak darah.
Hasil pewarnaan juga menunjukkan bahwa penambahan fuchsin dan pemanasan sputum sebelum pembuatan sediaan dapat mewarnai bakteri $M$ tuberculosis.Warna bakteri merah dan latar belakang biru, seperti tampak pada gambar 1 dibawah ini 


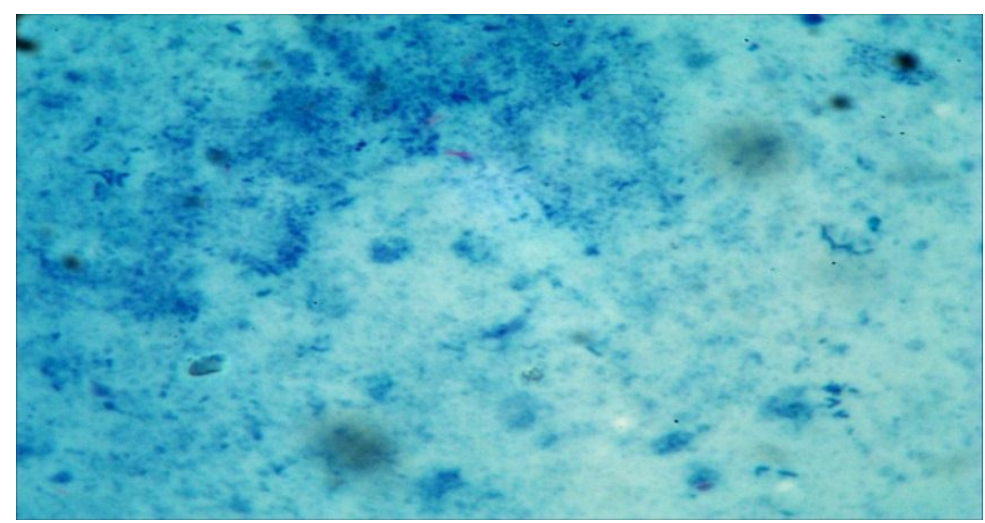

Gambar 1.Hasil pewarnaan menggunakan suhu $60^{\circ} \mathrm{C}$

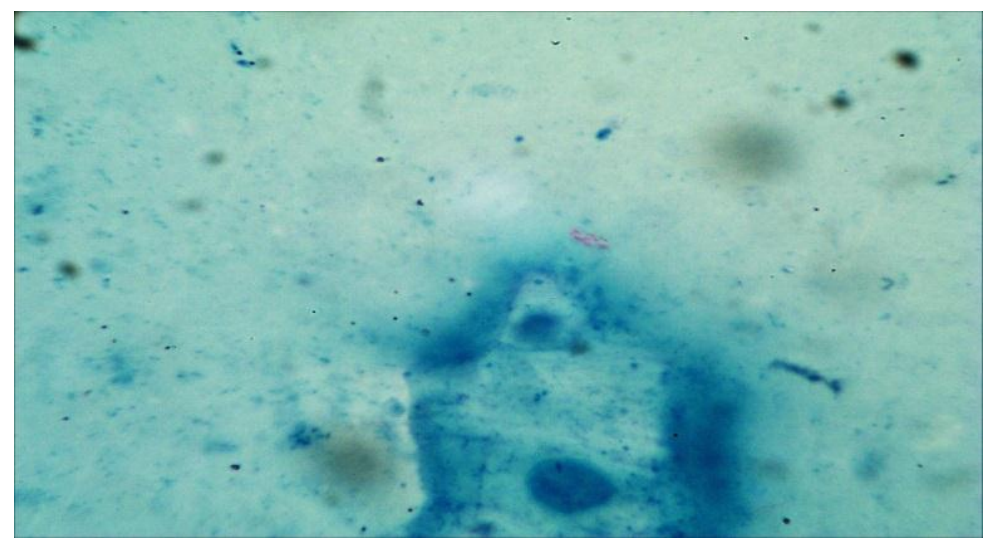

Gambar 2.Hasil pewarnaan menggunakan suhu $70^{\circ} \mathrm{C}$

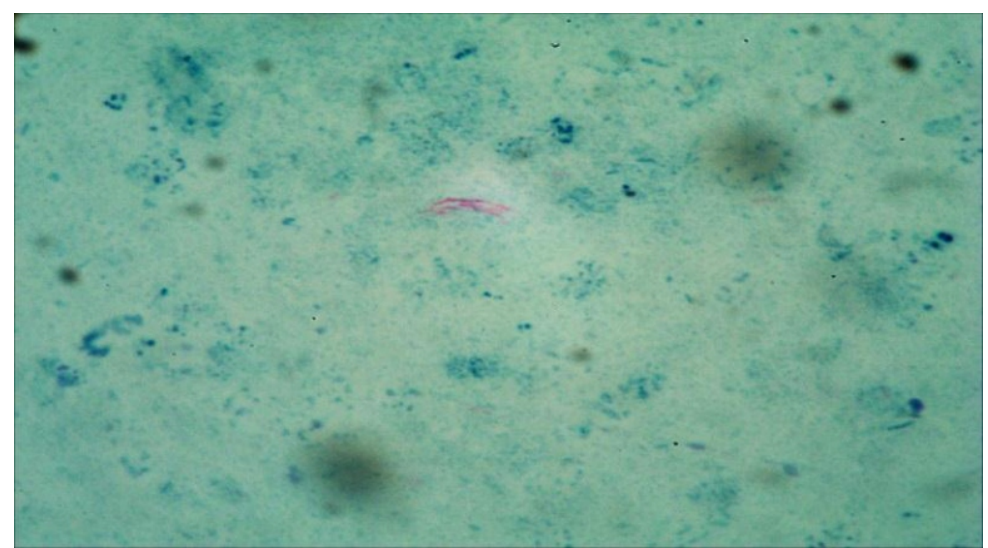

Gambar 3.Hasil pewarnaan menggunakan suhu $80^{\circ} \mathrm{C}$ 


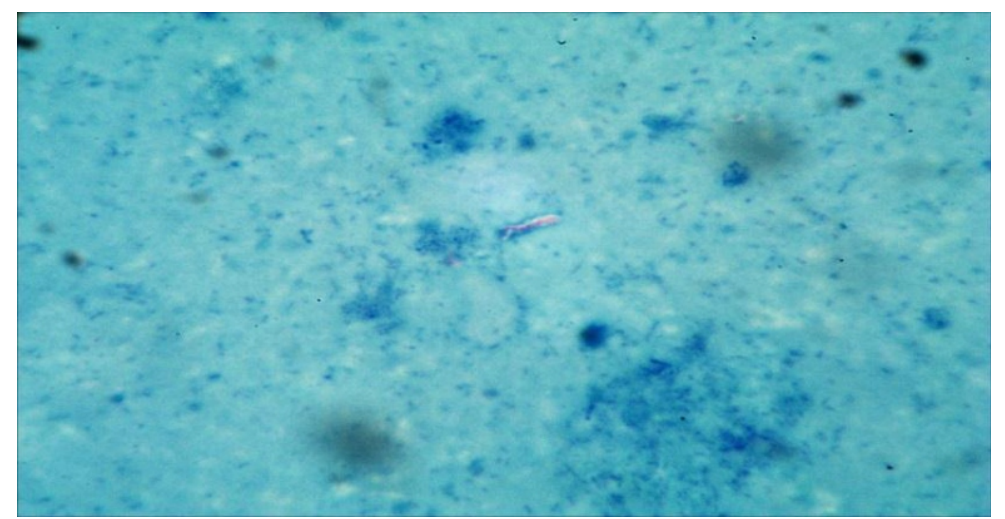

Gambar 4.Hasil pewarnaan menggunakan suhu $90^{\circ} \mathrm{C}$

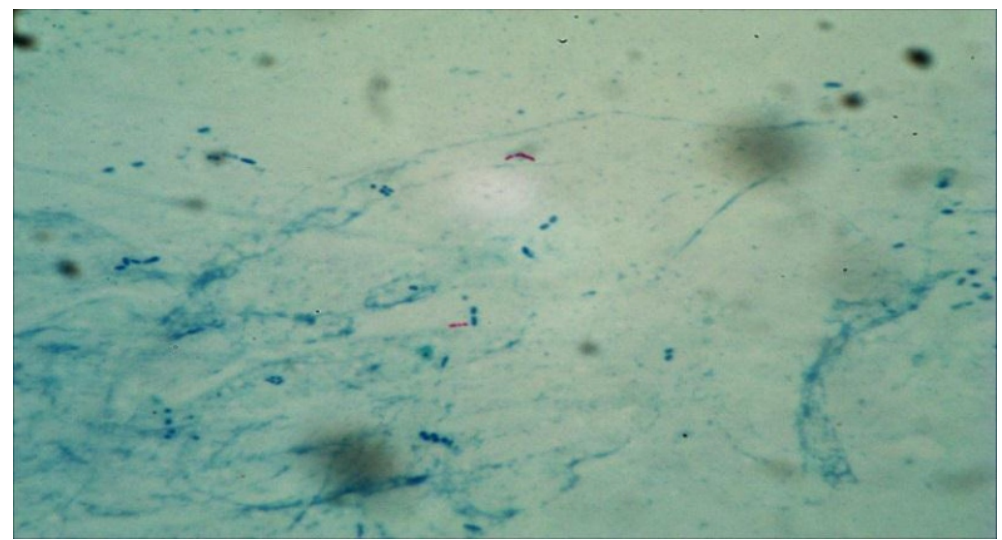

Gambar 5.Hasil pewarnaan ZiehlNeelsen (Kontrol)

Untuk mengetahui adanya perbedaan hasil pewarnaan antara beberapa suhu yang digunakan $\left(60^{\circ} \mathrm{C}, \quad 70^{\circ} \mathrm{C}, \quad 80^{\circ} \mathrm{C}, \quad 90^{\circ} \mathrm{C}\right)$ terhadap hasil pewarnaan BTA metode Ziehl Neelsen (kontrol) dilakukan uji Kruskal Wallis pada confident interval 95\% (alpha $=0,05)$ didapat hasil uji kruskal Wallis menunjukkan nilai $\mathrm{P}>0.05$ ( $\mathrm{p}=0,301)$ yang berarti terima H0 dan tolak Ha (tabel 2). Hal tersebut menunjukkan bahwa tidak ada perbedaan yang bermakna antara hasil pewarnaan BTA dengan menggunakan sputum yang telah diberikan karbol fuchsin dan dipanaskan menggunakan beberapa suhu dengan hasil pewarnaan BTA metode Ziehl Neelsen. 
Tabel 2. Hasil uji Kruskal Wallis

\begin{tabular}{cccc}
\hline & Suhu & $\mathrm{N}$ & Mean Rank \\
\hline Hasil & Kontrol & 10 & 31.40 \\
& $60 \mathrm{C}$ & 10 & 25.75 \\
& $70 \mathrm{C}$ & 10 & 21.15 \\
& 80C & 10 & 28.05 \\
$90 \mathrm{C}$ & 10 & 21.15 \\
& Total & 50 & \\
\hline
\end{tabular}

\begin{tabular}{lr}
\hline & \multicolumn{2}{c}{ Hasil } \\
\hline Chi-Square & 4.871 \\
Df & 4 \\
Asymp. Sig. & .301 \\
\hline
\end{tabular}

Pada tabel 1 dapat terlihat

bahwa dari 40 preparat hasil pewarnaan BTA yang dipanaskan menggunakan beberapa suhu pemanasan ditemukan sebanyak 36 preparat (90\%) menunjukkan hasil bakteri Mycobacterium tuberculosis dapat diwarnai dan 4 preparat $(10 \%)$ menunjukkan hasil bakteri Mycobacterium tuberculosis tidak terwarnai. Hal ini berarti bahwa pewarnaan BTA dengan menggunakan metode ini dapat mewarnai sel bakteri Mycobacterium tuberculosis. Sedangkan adanya preparat BTA yang sel bakterinya tidak terwarnai mungkin disebabkan karena sputum no 10 memiliki karakteristik sputum yang encer (tidak purulen) dan mengandung banyak darah. Sputum yang encer pada saat ditambahkan karbol fuchsin dan dihomogenkan menjadi semakin encer yang bila dibuat sediaan akan didapat hasil yang kurang baik dan sangat tipis sehingga bila telah melalui proses pewarnaan akan didapat hasil yang sangat tipis atau tidak terwarnai. Selain itu banyaknya darah pada sputum bila dipanaskan akan padat dan berwarna kehitaman sehingga sehingga pada saat dibuat sediaan tidak mendapat hasil yang baik.

Bila dibandingkan dengan dengan gambar 1,2 dan 4 tampak hasil pewarnaan gambar 3 adalah yang paling baik dan hasilnya sama dengan kontrol (gambar 5), dengan demikian menunjukkan bahwa pemanasan dengan suhu $80^{\circ} \mathrm{C}$ merupakan suhu yang paling

baikkarenabakteriberwarnamerahjelas, leukosit dan latar belakang berwarna biru. Hasil ini sesuai dengan pernyataan Lumb.R, Bastian.I, danYamin.Gtahun 2007 menyatakan bahwa dinding sel Mycobacterium tuberculosis mengandung lemak sehingga sukar diwarnai. Agar dapat menyerap zatwarna maka pemanasan sampai menguap dapat 
membuka lapisan lilin pada dinding sel sehingga zat warna dapat masuk.

Hasil uji statistik terhadap hasil penelitian diperoleh hasil tidak ditemukan perbedaan yang bermakna antara masing masing suhu pemanasan sputum terhadap hasil pewarnaan BTA $(p=0,301)$. Hasil ini menunjukkan bahwa hasil pewarnaan pada masing masing suhu dan kontrol mempunyai hasil pewarnaan yang sama sehingga untuk membuat pewarnaan dengan cara ini dapat menggunakan suhu $60^{\circ} \mathrm{C}, 70^{\circ} \mathrm{C}, 80^{\circ} \mathrm{C}$ atau $90^{\circ} \mathrm{C}$. Hal ini dapat terjadi karena pemanasan merupakan cara yang digunakan untuk membuka dinding sel bakteri. Batas waktu pemanasan ditandai dengan menguap dan tidak boleh sampai mendidih bertujuan agar tidak merusak sel bakteri Mycobacterium tuberculosis. Sesuai dengan pernyataan Jawetz, dkk (2013) bahwa Mycobacterium tuberculosis merupakan bakteri tahan asam yang mempunyai dinding sel yang kaya akan peptidoglikan dan lipid sehingga tidak dapat menyerap zat warna. Pemanasan sangat dibutuhkan agar BTA dapat menyerap zat warna.

Hasil penelitian juga menunjukkan kelebihan dan kelemahan dari pembuatan sediaan menggunakan sputum yang telah ditambahkan karbol fuchsin dan dipanaskan terlebih dahulu. Kelebihan dari cara ini adalah dapat mengurangi penularan TB pada petugas yang menangani pemeriksaan BTA di laboratorium. Hal ini disebabkan berkurangnya waktu kontak petugas dengan sputum segar. Coilling yang dilakukan menggunakan sputum segar membutuhkan waktu yang cukup lama sehingga kontak petugas menjadi lebih lama, namun dengan metode ini, coiling dilakukan pada saat bakteri dalam sputum sudah mati karena penambahan karbol fuksin dan pemanasan sehingga petugas sama sekali tidak kontak dengan sputum segar pada saat pembuatan preparat pewarnaan BTA.

Selain itu apabila dibutuhkan pengulangan pembuatan pewarnaan maka bila menggunakan metode ini memerlukan waktu yang lebih cepat. Hal ini disebabkan karena petugas tidak harus menunggu pemanasan ditempat pewarnaan sampai menguap dan menunggunya menyerap pewarnaan selama 5 menit karena setelah sputum diberi karbol fuksin dan dimasukkan ke waterbath untuk dipanaskan lagi. Petugas cukup memulai pekerjaan dari membuat sediaan lalu memberi metilenbiru yang hanya 10-30 detik.

Selain kelebihan ditemukan pula beberapa kelemahan dari penelitian ini yang harus diteliti lebih lanjut untuk penyempurnaannya yaitu :

1. Warna merah lebih tipis 
Pada penelitian ini ditemukan beberapa hasil pewarnaan dengan warna sel bakteri yang tipis. Hal ini dapat disebabkan karena perbandingan antara zat warna dengan sputum belum sesuai atau konsentrasi karbol fuksin yang digunakan kurang pekat. Menurut Utjie $\mathrm{R}$ dan Harun $\mathrm{H}$ tahun2015 bahwa karbol fuhsin merupakan zat warna dasar yang mengandung fenol yang berfungsi untuk melarutkan dinding sel sehingga kepekatan karbol fuksin sangat mempengaruhi kejelasan warna sel bakteri. Konsentrasi karbol fuksin yang digunakan pada penelitian ini $0,3 \%$ sama dengan untuk metode Ziehl Neelsen.

2. Sputum menjadi lebih encer

Penambahan Karbol fuksin menyebabkan encernya sputum bila telah dihomogenisasi sehingga menyebabkan kesukaran dalam melakukan coilling. Bila digunakan sputum yang purulen masih mendapatkan hasil yang baik karena setelah dipanaskan sputum berwarna merah dan masih kental sehingga lebih mudah di coilling namun kesukaran lebih besar terjadi bila sputum yang digunakan tidak purulen. Kumala W tahun 2006 menyatakan bahwa sputum yang digunakan untuk pemeriksaan BTA adalah sputum yang kental dan berwarna hijau kekuningan. Banyaknya sputum yang dikumpulkan untuk pemeriksaan BTA adalah 3-5 $\mathrm{ml}$ dan bila diamati menggunakan mikroskop ditemukan 5000 bakteri/ml.

\section{SIMPULAN}

Berdasarkan hasil penelitian yang diperoleh dengan cara memanaskan sputum yang telah ditambahkan karbol fuksin dengan beberapa suhu dapat disimpulkan bahwa :

1. Penambahan karbol fuchsin dan pemanasan sputum sebelum pembuatan sediaan dapat mewarnai bakteri Mycobacterium tuberculosis.

2. Tidak ditemukan perbedaan yang bermakna antara beberapa suhu yang digunakan untuk pemanasan sputum yang telah ditambahkan karbol fuksin terhadap hasil pewarnaan BTA.

Hasil penelitian ini masih memiliki banyak kekurangan dan untuk menyempurnakan nya disarankan untuk melakukan penelitian lebih lanjut.

\section{DAFTAR RUJUKAN}

Aditama TY dan Luthni E, 2012. Buku petunjuk Teknik Pemeriksaan laboratorium Tuberculosis, Edisi II, Laboratorium Mikobakteriologi RS Persahabatan Jakarta, h:3

Buntuan V, 2014. Gambaran basil TahanAsam (BTA) Positif Pada Penderita Diagnosa Klinis Tuberculosis Paru Di Rumah Sakit Islam Siti Maryam Manado Periode Januari 2014 S/D Juni 2014.Jurnal eBiomedik (eBM), Vol 2(2):593 
Depkes RI. 2007. Pedoman Nasional Penangulangan Tuberkulosis. Jakarta.

EddinMG, Khairsyal o, Usman E. 2015. Profil kasus Tuberkulosis Paru di Instalasi Rawat Inap Paru RSUP Dr. M. djamil padangPeriode 1 januari 2010 - 1 Desember 2011. Jurnal kesehatan Andalas ,Vol 4(3):888

Jawetz, E, Melnick.JL., Adelberg.E.A., 2013, Mikrobiologi Untuk Profesi Kesehatan, Edisi 22, EGC, Jakarta

Kumala.W, 2006. Diagnosis Laboratorium Mikrobiologi Klinik, Penerbit Universitas Trisakti, Jakarta

Lumb.R, Bastian.I, Yamin.G, 2007, Panduan Bagi Petugas Laboratorium. Pemeriksaan Mikroskopis Tuberculosis, Cetakan 2, Departemen kesehatan, Jakarta

Misnadiarly,2006.Mycobacterium tuberculosis atipik, Jakarta, h: 81

Silvani H, Sureskiarti E, 2016. Hubungan Peran

Aktif

Keluarga
SebagaiPengawas Minum Obat (PMO DenganAngka Kekambuhan TB Paru Di Ruang Seruni RSUD Abdul WahabSjahranie Samarinda. Jurnal Ilmu Kesehatan, Vol 4(2):66

Susanti D, Kountul C, Buntuan V, 2013. Pemeriksaan Basil Tahan Asam (BTA) Pada Sputum Penderita Batuk $>2$ Minggu Di Poliklinik PenyakitDalam BLU RSUP Prof Dr.R.D Kandou Manado.Jurnal eClinik (eCl), Vol 1(1)

Susanto AD. 2010. Analisis Kadar Interferon Gamma Pada Penderita Tuberkulosis Paru Dan Orang Sehat.Jurnal Respirologi Indonesia, Vol30 : 119

Utji R, Harun H. 2015, Kuman Tahan Asam dalam Buku Ajar Mikrobiologi Kedokteran, Bina Rupa Aksara, Jakarta.

www.surveyland-dinkesdki 21/02/2012. Pencapaian MDG'S meningkat. 20/02/2016 
